\title{
Complications following breast cancer therapy in the adult spina bifida population: A case report
}

\author{
Nathan Y. Hoy, MD; Peter Metcalfe, MD
}

Division of Urology, University of Alberta, Edmonton, AB

Cite as: Can Urol Assoc J 2013;7(11-12):e761-3. http://dx.doi.org/10.5489/cuaj.503

Published online November 8, 2013.

\section{Abstract}

Survival to adulthood in spina bifida has greatly increased with the advent of modern therapies. With this prolonging of life expectancy, patients are exposed to the risk of adult onset malignancies and the complications of subsequent treatment. We present the case of a 66-year-old woman born with a terminal lipomyelomeningocele, presenting with new fecal incontinence and a desire to undivert her ileal conduit. The deterioration was attributed to chemotherapy for breast cancer. We highlight the urologic challenges of breast cancer management in the neurogenic bowel population, as well as the utility of an adult spina bifida clinic. To the best of our knowledge, this is the first case report of a spina bifida patient presenting with fecal and urinary complications from breast cancer chemotherapy.

\section{Introduction}

Much progress has been made with respect to life expectancy in spina bifida patients, such that many children are living into their adult years with the condition. ${ }^{1}$ It has been wellestablished that early management of spina bifida complications, including fecal and urinary incontinence, is essential towards maximizing functional outcomes. ${ }^{2}$ However, as a result of the early treatments and progressively longer life expectancies, patients face potential complications arising from the treatment of adult onset malignancies.

We present the case of a 66-year-old woman born with a terminal lipomyelomeningocele, presenting with new fecal incontinence and a desire to undivert her ileal conduit. The deterioration was attributed to radiation and chemotherapy for breast cancer. We highlight the urologic challenges of breast cancer management in the neurogenic bowel population, as well as the utility of an adult spina bifida clinic.

\section{Case report}

A 66-year-old female with a congenital terminal lipomyelomeningocele presented to the adult spina bifida clinic. As an infant, she was treated with a radioactive surface paste for a spina bifida. She experienced urinary incontinence throughout her childhood and it was not until she was 26 that a ureterostomy was completed. This was replaced with an ileal conduit 7 years later.

The patient remained functionally stable until 2004, when she was diagnosed with left sided breast cancer stage IIA, T2N0M0. Subsequently, she underwent a lumpectomy with axillary lymph node dissection followed by a complete left radical mastectomy. She was also administered 6 cycles of FEC 100 (F: 5-flurouracil, E: epirubicin at $100 \mathrm{mg} / \mathrm{m}^{2}$; $\mathrm{C}$ : cyclophosphamide) adjuvant chemotherapy at the end of the year, then 20 doses of radiation to the left chest wall. Although tolerated relatively well, the chemotherapy did result in a distal neuropathy and decreased sensation in her fingers and toes. It is likely that the chemotherapy caused a sensory neuropathy of her bowels that caused her constipation and subsequent overflow incontinence.

Three years after her chemotherapy and radiation treatments, she began experiencing worsening fecal control, likely secondary to decreased perineal sensation, and was referred by her urologist to our adult spina bifida clinic. She described symptoms of alternating 3 to 4 days of constipation and a day of fecal incontinence. Her fecal control prior to the breast cancer treatments was regular continence with the occasional incontinent episode only once every 3 months. As a child, she had tried enemas and manual disimpaction. However, since the onset of the incontinence, she was unable to perform these independently and did not see enemas and disimpactions as viable long-term options.

On initial evaluation at the adult spina bifida clinic, she reported a history of progressive, incapacitating back pain, radiating down her legs bilaterally over the past year. 
Physical exam demonstrated tight heel cords, exaggerated foot arches, and claw toe deformities. A magnetic resonance imaging performed in 2009 revealed a low-lying cord tethered at S2 due to a terminal lipomyelomeningocele. By early 2010, this was surgically released by pediatric neurosurgery with resolution of her leg pain symptoms. This was complicated by a cerebrospinal fluid leak and prolonged hospital stay.

In May 2010, she underwent surgery for an ileal conduit revision and definitive management of her fecal incontinence. Preoperative urodynamics demonstrated a low-pressure, small capacity $(<100 \mathrm{cc})$ bladder. However, accurate assessment was difficult secondary to significant leakage.

Due to the defunctionalized nature of her bladder and the distant exposure to an unknown quantity of radiation, we elected to perform a cystectomy. We converted her ileal conduit to a continent urinary reservoir with a Monti limb. Given her history of appendectomy, we fashioned her Malone antegrade continence enema (MACE) with a Monti catheterizable channel into her transverse colon.

Postoperative recovery was prolonged ( 17 days in hospital), as she was quite limited in her ambulation. Her catheters were removed 3 weeks after surgery and she was able to perform the catheterizations without any difficulty. Her MACE was functioning well, with daily flushes of one tablespoon of polyethylene glycol and 750 cc of tap water. However, she began leaking from her Monti channel after 4 weeks of continence. Urodynamic studies demonstrated filling at 25 to $60 \mathrm{~mL} / \mathrm{min}$ for a total of $306 \mathrm{~mL}$. End-filling pressure measurements were zero, indicating an incompetent valve and failing anti-incontinence mechanisms. Fluoroscopy was consistent with the channel having pulled away from the reservoir.

In April 2011, following an unsuccessful deflux injection, a Monti revision procedure was completed utilizing a modified spiral Casale over a $12 \mathrm{Fr}$ catheter. Follow-up urodynamic testing showed a filling rate of $45 \mathrm{~mL} / \mathrm{min}$ for a total of $633 \mathrm{~mL}$ and an end-filling pressure of $13 \mathrm{~cm}$ of water. Her course was further complicated by a ventral incisional hernia requiring surgical repair in January 2012. Her MACE and Monti catheterizable channel are currently functioning as expected.

\section{Discussion}

To the best of our knowledge, this is the first case report of a spina bifida patient presenting with fecal and urinary complications from breast cancer chemotherapy. Survival to adulthood in spina bifida is now $85 \%$ to $90 \%{ }^{3}$ With this increase in life expectancy, patients are exposed to the risk of adult onset malignancies and the complications of subsequent treatment.

Urinary incontinence and fecal constipation and incontinence are known effects of spina bifida resulting from disruption of central nervous system control of regulating mechanisms. ${ }^{4}$ The initiating event for the deterioration of the patient's fecal control was the FEC 100 chemotherapy. The FEC 100 regimen has been shown to be an efficacious adjuvant treatment for breast cancer. ${ }^{5}$ It was not until 3 years post-treatment that the patient began experiencing worsening of her fecal continence secondary to a sensory neuropathy of her bowels with subsequent overflow incontinence. Sensory neuropathy was noted as a side effect of neoadjuvant FEC therapy in $5 \%$ of patients in a study by Robidoux and colleagues, with 62 patients receiving at least 1 cycle. $^{6}$ In a follow-up study of the long-term side effects of radiation therapy, all the effects were limited to the local field of radiation, including brachial plexopathy, rib fractures, and pericarditis among others. ${ }^{7}$ Thus, it is highly unlikely that the radiation had any significant impact on the fecal changes.

The management of our patient also raises a number of unique issues. She elected to undergo a MACE procedure for her fecal dysfunction. Although MACE has been successfully used in adults, at age 66, she was older than most undergoing the procedure. ${ }^{8}$ Having had a prior appendectomy, she also elected for a Monti catheterizable channel and augmentation of her ileal conduit. Her bladder could have potentially been augmented and used as a urinary reservoir. Her uretero-ileal anastomoses were functioning perfectly; therefore, we wished to avoid a re-implantation and risk stenosis of her new ureterovesical junction. As well, her ileal conduit was created for a primary indication of incontinence, thus the use of her native detrusor would have required a formal bladder neck procedure. The continent reservoir required the least amount of manipulation and the chance of continence via the cutaneous channel was excellent. Lastly, the bladder had been exposed to an indeterminate amount of radiation, increasing the inherent risk of malignant degeneration, which would have been increased by augmentation.

Gowda and colleagues demonstrated adult outcomes from continent catheterizable channels to be comparable to pediatric outcomes. ${ }^{9}$ They found that stomal incontinence may occur more frequently with Monti ileal conduits than using the appendix for the catheterizable channel, as was the case with our patient.

Lastly, this case highlights the importance of a multidisciplinary adult spina bifida clinic. Our patient was referred to the adult spina bifida clinic because of the comprehensive, multidisciplinary care provided. We were able to address all her neurologic, urologic, and rehabilitation needs. Dicianno and colleagues demonstrated that a multidisciplinary dedicated spina bifida team provides optimal care for children. ${ }^{10}$ However, far fewer comprehensive adult spina bifida clinics exist. $^{10}$

As spina bifida patients age, they present a variety of unique challenges. For instance, a recent systematic review found total continence in this population to be only $37.7 \%$ 
(449/1192; range $8 \%-85 \%)$, despite a variety of pediatric treatments. ${ }^{11}$ Patients face not only medical issues, such as progressively worsening orthopedic deformities, or latemanifesting neurologic deficits, but also many psychosocial issues, including aging parents who can no longer be the primary caregivers, struggles with disease stigma, and developing independence. ${ }^{10,12}$ From a urologic standpoint, Persun and colleagues recommend yearly renal ultrasound and serum creatinine to monitor for renal dysfunction secondary to elevated detrusor pressures, or decrease in functional bladder capacity. ${ }^{13}$ Adult patients with spina bifida have a lifelong elevated risk of developing renal damage due to altered bladder behaviour.

Another long-term concern for these patients is the risk of bladder cancer. A review by Austin and colleagues documented 19 published cases of spina bifida patients developing bladder cancer at a median age of 35 years. ${ }^{14}$ Of these patients, $37 \%$ had a bladder augmentation. Augmentation with bowel has been associated with a bladder cancer incidence of $1.2 \%$ to $3.8 \% .^{15}$ The most interesting finding from these studies was that the bladder malignancies, regardless of augmentation, were more advanced stage and invasive, which for reasons unknown, differs markedly from the general population. Thus, it is of paramount importance that spina bifida patients continue regular urologic follow-up into adulthood. This is a population at risk for developing more invasive bladder cancer at a younger age and many have also undergone bladder augmentation, which further increases the risk of bladder cancer.

\section{Conclusion}

Overall, this case report highlights a rare complication of breast cancer chemotherapy on the fecal function of a spina bifida patient. Adult-onset diseases, such as breast cancer, can complicate the course of spina bifida patients who are surviving increasingly longer, and medical professionals should be cognizant of this. With this survival progression, dedicated adult spina bifida clinics are necessary to provide the comprehensive, multifaceted care these patients require. Lastly, this case illustrates that several surgical techniques commonly used in pediatrics to manage urinary and fecal dysfunction should be considered in the adult population, despite the increased potential for complications.
Competing interests: Dr. Hoy and Dr. Metcalfe declare no competing financial or personal interests.

This paper has been peer-reviewed.

\section{References}

1. Oakeshott P, Hung GM. Long-term outcome in open spina bifida. Br J Gen Pract 2003;53;632-6.

2. McDonald CM. Rehabilitation of children with spinal dysraphism. Neurosurg Clin N Am 1995;6:393-412.

3. Dillon CM, Davis BE, Duguay $S$, et al. Longevity of patients born with myelomeningocele. Eur J Pediatr Surg 2000;10:33-4. http://dx.doi.org/10.1055/s-2008-1072412

4. Matsuno D, Yamazaki Y, Shiroyanagi Y, et al. The role of the retrograde colonic enema in children with spina bifida: is it inferior to the antegrade continence enema? Pediatr Surg Int 2010;26:529-33. http:// dx.doi.org/10.1007/s00383-010-2585-6

5. French Adjuvant Study G. Benefit of a high-dose epirubicin regimen in adjuvant chemotherapy for nodepositive breast cancer patients with poor prognostic factors: 5 -year follow-up results of French Adjuvant Study Group 05 randomized trial. I Clin Oncol 2001;19:602-11.

6. Robidoux A, Buzdar AU, Quinaux E, et al. A phase II neoadjuvant trial of sequential nanoparticle albuminbound paclitaxel followed by 5-fluorouracil/epirubicin/cyclophosphamide in locally advanced breast cancer. Clin Breast Cancer 2010;10:81-6. http://dx.doi.org/10.3816/CBC.2010.n.011

7. Pierce $S M$, Recht A, Lingos $T$, et al. Long-term radiation complications following conservative surgery (CS) and radiation therapy (RT) in patients with early stage breast cancer. Int I Radiat Oncol Biol Phys 1992;23:915-23. http://dx.doi.org/10.1016/0360-3016(92)90895-0

8. Lefevre $J H$, Parc $Y$, Giraudo $G$, et al. Outcome of antegrade continence enema procedures for faecal incontinence in adults. Br J Surg 2006;93:1265-9. http://dx.doi.org/10.1002/bjs.5383

9. Gowda BD, Agrawal V, Harrison SC. The continent, catheterizable abdominal conduit in adult urological practice. BJU Int 2008;102:1688-92. http://dx.doi.org/10.1111/j.1464-410X.2008.07885.x

10. Dicianno BE, Kurowski BG, Yang JM, et al. Rehabilitation and medical management of the adult with spina bifida. Am J Phys Med Rehabil 2008;87:1027-50. http://dx.doi.org/10.1097/ PHM.0b013e31818de070

11. Veenboer PW, Bosch JL, van Asbeck FW, et al. Upper and lower urinary tract outcomes in adult myelomeningocele patients: a systematic review. PLoS ONE 2012;7:e48399. http://dx.doi.org/10.1371/ journal.pone.0048399

12. Ridosh $M$, Braun $P$, Roux $G$, et al. Transition in young adults with spina bifida: a qualitative study. Child Care Health Dev 2011;37:866-74. http://dx.doi.org/10.1111/i.1365-2214.2011.01329.x

13. Persun ML, Ginsberg PC, Harmon JD, et al. Role of urologic evaluation in the adult spina bifida patient. Urol Int 1999;62:205-8. http://dx.doi.org/10.1159/000030396

14. Austin JC, ElliottS, Cooper CS. Patients with spina bifida and bladder cancer: atypical presentation, advanced stage and poor survival. J Urol 2007;178:798-801. http://dx.doi.org/10.1016/i.juro.2007.05.055

15. Soergel $T$, Cain M, Misseri R, et al. Transitional cell carcinoma following augmentation cystoplasty for the neuropathic bladder. J Urol 2004;172:1649-51. http://dx.doi.org/10.1097/01. ju.0000140194.87974.56

Correspondence: Dr. Peter Metcalfe, Division of Urology, University of Alberta, Suite 400 Hys Centre, 11010-101 St., Edmonton, AB T5H 4B9; pmetcalf@ualberta.ca 